\title{
Adaptive Fuzzy Output-Feedback Method Applied to Fin Control for Time-Delay Ship Roll Stabilization
}

\author{
Rui Bai \\ School of Electrical Engineering, Liaoning University of Technology, Jinzhou, Liaoning 121001, China \\ Correspondence should be addressed to Rui Bai; broffice@126.com
}

Received 4 March 2014; Accepted 20 April 2014; Published 6 May 2014

Academic Editor: Hak-Keung Lam

Copyright (C) 2014 Rui Bai. This is an open access article distributed under the Creative Commons Attribution License, which permits unrestricted use, distribution, and reproduction in any medium, provided the original work is properly cited.

\begin{abstract}
The ship roll stabilization by fin control system is considered in this paper. Assuming that angular velocity in roll cannot be measured, an adaptive fuzzy output-feedback control is investigated. The fuzzy logic system is used to approximate the uncertain term of the controlled system, and a fuzzy state observer is designed to estimate the unmeasured states. By utilizing the fuzzy state observer and combining the adaptive backstepping technique with adaptive fuzzy control design, an observer-based adaptive fuzzy output-feedback control approach is developed. It is proved that the proposed control approach can guarantee that all the signals in the closed-loop system are semiglobally uniformly ultimately bounded (SGUUB), and the control strategy is effective to decrease the roll motion. Simulation results are included to illustrate the effectiveness of the proposed approach.
\end{abstract}

\section{Introduction}

Stabilization of ship roll motion induced by wave disturbances has received considerable attention. This is because excessive roll motion would make the crew feel uncomfortable and may also cause damage to the cargoes and equipment on board. Various types of antirolling devices are introduced to reduce undesirable wave-induced roll motion [1]. Stabilizing fins are the most effective and popular antirolling devices in use. Stabilizing fins have been used extensively for high speed vessels, particularly on war ships and cruise ships. Lift forces are generated by the fins and a couple is produced to counteract the wave-induced roll moment. Since the lift force depends on the relative inflow speed, the stabilizing fins are effective only when the ships are sailing at relatively high speed. Some methods have been introduced. A multivariable control approach to the design of antirolling fins for a war ship has been proposed, where the rudder and the fins are considered simultaneously to reduce the wave-induced roll motion without sacrificing the yaw control performance [2]. Fuzzy control method basing on empirical if-then rules has also been introduced to the design of the fin stabilization system [3]. Application of the adaptive LQ method to the stabilization for a monohull ship is reported in [4], and an $\mathrm{H}-\infty$ control design method has been employed in the design of a robust stabilizing fin controller [5]. A novel ship stabilizing fin controller based on the internal model control (IMC) method was proposed in [6].

Adaptive backstepping technique is an important control method in the last twenty years. The backstepping design provides a systematic framework for the design of tracking and regulation strategies, suitable for a large class of nonlinear systems [7-11]. Some fin control methods based on backstepping technique have been proposed $[12,13]$. A nonlinear robust controller was designed by using backstepping and closedloop gain shaping algorithms to improve the robustness of fin stabilizer controller. A novel sliding backstepping controller was designed to decrease the roll motion of fin stabilizer control system for the system with nonlinear disturbance observer. However, the control methods in $[12,13]$ are all based on the assumption that angular velocity in roll is measured. As what authors stated in [14-16], in practice, the state variables are often unmeasured for many nonlinear systems. Therefore, the existing approaches in $[12,13]$ cannot be implemented for the fin control system, in which the angular velocity is not measured. 
Motivated by the above observation, this paper investigates the adaptive fuzzy output-feedback control problem of the time-delay ship roll stabilization. The fuzzy logic system can be used to approximate the unmodeled plant [17-19]. In this paper, assuming that angular velocity in roll cannot be measured, an adaptive fuzzy output-feedback control design problem is investigated, and a fuzzy state observer is designed to estimate the unmeasured states. By utilizing the fuzzy state observer and combining the adaptive backstepping technique with adaptive fuzzy control design, an observerbased adaptive fuzzy output-feedback control approach is developed. It is proved that the proposed control approach can guarantee that all the signals in the closed-loop system are SGUUB.

The main contribution of this paper is the innovation and application value of the proposed controller for the ship roll motion. Compared with other control strategies, the unmeasured angular velocity is considered during the design process of the controller, and the control strategy is effective to decrease the roll motion.

\section{Nonlinear Model Descriptions of Fin Control System}

In this paper, we consider the following nonlinear systems [12, 13]:

$$
\begin{gathered}
\left(I_{x x}+J_{x x}\right) \ddot{\varphi}+\delta_{N} \dot{\varphi}+\delta_{W} \dot{\varphi}|\dot{\varphi}|+D h \varphi\left[1-\left(\frac{\varphi}{\varphi_{v}}\right)^{2}\right] \\
=M_{c}+M_{W}, \\
I_{x x}+J_{x x}=\frac{D B^{2}}{g}\left(0.3085+\frac{0.0227 B}{d}-\frac{0.00043 L}{100}\right)^{2}, \\
\delta_{N}=\frac{2 n_{1} \sqrt{D h\left(I_{x x}+J_{x x}\right)}}{\pi}, \\
\delta_{W}=\frac{3 n_{2}\left(I_{x x}+J_{x x}\right)}{4}, \\
M_{C}=-\rho v^{2} A_{f} l_{f} C_{L}^{a}\left(a_{f}+\hbar+\frac{\dot{\varphi} l_{f}}{v}\right), \\
M_{W}=-D h a_{e},
\end{gathered}
$$

where $\varphi$ is rolling angle of ship; $I_{x x}$ and $J_{x x}$ are inertias moments and the added inertia moments of the own ship; $\delta_{N}$ and $\delta_{W}$ are damping factors; $D$ is the tonnage of ship; $h$ is initial metacentric height; $\varphi_{v}$ is flooding angle; $M_{C}$ is control moment of the fin stabilizer; $M_{W}$ is the moment of sea wave act on ship; $g$ is gravitational acceleration; $B$ is width of ship; $L$ is length between tow-column of ship; $d$ is draught; $n_{1}$ and $n_{2}$ are test coefficients; $\rho$ is fluid density; $v$ is ship's speed; $A_{f}$ is the area of fin; $l_{f}$ is the acting force arm of the stabilizer fin; $C_{L}^{a}$ is the slope of lift coefficient; $a_{f}$ is the rotation angle of the stabilizer fin; $a_{e}$ is significant wave angle. $\hbar=\varphi(t-\tau(t))$ is a time-delay term, and $\tau(t)$ is an unknown bounded time delay satisfying $|\tau(t)| \leq \bar{\tau}$ and $\dot{\tau}(t) \leq \tau^{*} \leq 1$, where $\bar{\tau}$ and $\tau^{*}$ are known constants.

From (1), we have

$$
\ddot{\varphi}=a_{1} \varphi+a_{2} \varphi^{3}+a_{3} \dot{\varphi}+a_{4} \dot{\varphi}|\dot{\varphi}|+b a_{f}+b \hbar+c a_{e},
$$

where $a_{1}=-D h /\left(I_{x x}+J_{x x}\right), a_{2}=D h / \varphi_{v}^{2}\left(I_{x x}+J_{x x}\right), a_{3}=$ $-\delta_{N} /\left(I_{x x}+J_{x x}\right)-\rho v^{2} A_{f} l_{f}^{2} C_{L}^{a} /\left(I_{x x}+J_{x x}\right) v, a_{4}=-\delta_{W} /\left(I_{x x}+\right.$ $\left.J_{x x}\right), \quad b=-\rho v^{2} A_{f} l_{f} C_{L}^{a} /\left(I_{x x}+J_{x x}\right)$ and $c=-D h /\left(I_{x x}+J_{x x}\right)$.

Define $x=\left[x_{1}, x_{2}\right]^{T}=[\varphi, \dot{\varphi}]^{T}, y=\varphi=x_{1}$, and $u=a_{f}$; (2) can be rewritten as

$$
\begin{gathered}
\dot{x}_{1}=x_{2}, \\
\dot{x}_{2}=b u+f\left(x_{1}, x_{2}\right)+b \hbar+\Delta, \\
y=x_{1},
\end{gathered}
$$

where $f\left(x_{1}, x_{2}\right)=a_{1} x_{1}+a_{2} x_{1}^{3}+a_{3} x_{2}+a_{4} x_{2}\left|x_{2}\right|$ and $\Delta=c a_{e}$.

\section{Fuzzy Logic Systems}

We introduce the fuzzy logic systems. A fuzzy logic system (FLS) consists of four parts: the knowledge base, the fuzzifier, the fuzzy inference engine working on fuzzy rules, and the defuzzifier. The knowledge base for FLS comprises a collection of fuzzy if-then rules of the following form:

$$
\begin{aligned}
& R^{l}: \quad \text { If } x_{1} \text { is } F_{1}^{l} \text { and } x_{2} \text { is } F_{2}^{l} \text { and } \ldots \text { and } x_{n} \text { is } F_{n}^{l}, \\
& \text { Then } y \text { is } G^{l}, \quad l=1,2, \ldots, N,
\end{aligned}
$$

where $x=\left[x_{1}, \ldots, x_{n}\right]^{T}$ and $y$ are the fuzzy logic system input and output, respectively. Fuzzy sets $F_{i}^{l}$ and $G^{l}$ are associated with the fuzzy functions $\mu_{F_{i}^{l}}\left(x_{i}\right)$ and $\mu_{G^{l}}(y)$, respectively. $N$ is the rules number.

Through singleton function, center average defuzzification, and product inference [20], the fuzzy logic system can be expressed as

$$
y(x)=\frac{\sum_{l=1}^{N} \bar{y}_{l} \prod_{i=1}^{n} \mu_{F_{i}^{l}}\left(x_{i}\right)}{\sum_{l=1}^{N}\left[\prod_{i=1}^{n} \mu_{F_{i}^{l}}\left(x_{i}\right)\right]},
$$

where $\bar{y}_{l}=\max _{y \in R} \mu_{G^{l}}(y)$.

Define the fuzzy basis functions as

$$
\bar{\phi}_{l}=\frac{\prod_{i=1}^{n} \mu_{F_{i}^{l}}\left(x_{i}\right)}{\sum_{l=1}^{N}\left(\prod_{i=1}^{n} \mu_{F_{i}^{l}}\left(x_{i}\right)\right)} .
$$

Denote $\theta=\left[\bar{y}_{1}, \bar{y}_{2}, \ldots, \bar{y}_{N}\right]^{T}=\left[\theta_{1}, \theta_{2}, \ldots, \theta_{N}\right]^{T}$ and $\phi^{T}(x)=\left[\bar{\phi}_{1}(x), \ldots, \bar{\phi}_{N}(x)\right]$; then, fuzzy logic system (5) can be rewritten as

$$
y(x)=\theta^{T} \phi(x) .
$$

Lemma 1 (see [20]). Let $f(x)$ be a continuous function defined on a compact set $\Omega$. Then, for any constant $\varepsilon>0$, there exists an FLS (5) such as

$$
\sup _{x \in \Omega}\left|f(x)-\theta^{T} \phi(x)\right| \leq \varepsilon .
$$


The optimal parameter vector $\theta_{i}^{*}$ is defined as

$$
\theta^{*}:=\arg \min _{\theta \in R^{l}}\left\{\sup _{x \in D}\left|f(x)-\theta^{T} \phi(x)\right|\right\} .
$$

\section{Fuzzy State Observer Design}

The state $x_{2}=\dot{\varphi}$ in system (3) is not available for feedback. Therefore, a state observer should be established to estimate the states

$$
\begin{gathered}
\dot{\hat{x}}_{1}=\widehat{x}_{2}+k_{1}\left(y-\widehat{x}_{1}\right), \\
\dot{\hat{x}}_{2}=k_{2}\left(y-\widehat{x}_{1}\right)+\widehat{f}\left(x_{1}, \widehat{x}_{2}\right)+b u, \\
\hat{y}=\widehat{x}_{1},
\end{gathered}
$$

where $\widehat{f}\left(x_{1}, \widehat{x}_{2}\right)=\theta^{T} \phi\left(x_{1}, \widehat{x}_{2}\right)$ is the fuzzy logic system and is used to approximate the nonlinear term $f\left(x_{1}, \widehat{x}_{2}\right)$ in (11). System (10) can be rewritten as

$$
\begin{gathered}
\dot{\hat{x}}=A \hat{x}+K y+E_{2} \widehat{f}+E_{2} b u+E_{2} b \hbar, \\
\widehat{y}=E_{1}^{T} \widehat{x},
\end{gathered}
$$

where $\widehat{x}=\left[\widehat{x}_{1}, \widehat{x}_{2}\right]^{T}, A=\left[\begin{array}{ll}-k_{1} & 1 \\ -k_{2} & 0\end{array}\right], K=\left[k_{1}, k_{2}\right]^{T}, E_{1}^{T}=\left[\begin{array}{ll}1 & 0\end{array}\right]$, and $E_{2}=\left[\begin{array}{ll}0 & 1\end{array}\right]^{T}$.

The coefficients $k_{1}$ and $k_{2}$ are chosen such that the polynomial $p(s)=s^{2}+k_{1} s+k_{2}$ is a Hurwitz. Thus, given a $Q^{T}=Q>0$, there exists a positive definite matrix $P^{T}=P>0$ such that

$$
A^{T} P+P A=-Q .
$$

Let $e=x-\widehat{x}$ be observer error. Then, from (3) and (11), we have the observer errors equation

$$
\dot{e}=A e+E_{2} \Delta+E_{2} \tilde{f}+E_{2} b \hbar,
$$

where $\tilde{f}=f\left(x_{1}, x_{2}\right)-\widehat{f}\left(x_{1}, \widehat{x}_{2}\right)$. Consider the following Lyapunov candidate $V_{0}$ for (13) as

$$
V_{0}=e^{T} P e .
$$

The time derivative of $V_{0}$ along the solutions of (13) is

$$
\dot{V}_{0}=-e^{T} Q e+2 e^{T} P\left(E_{2} \Delta+E_{2} \tilde{f}+E_{2} b \hbar\right) .
$$

Since $f\left(x_{1}, x_{2}\right)=a_{1} x_{1}+a_{2} x_{1}^{3}+a_{3} x_{2}+a_{4} x_{2}\left|x_{2}\right|$ satisfies lipschitz condition, we have

$$
\left|f\left(x_{1}, x_{2}\right)-f\left(x_{1}, \hat{x}_{2}\right)\right| \leq L_{f}\left|x_{2}-\widehat{x}_{2}\right|,
$$

where $L_{f}$ is a constant. By using Young's inequality and $\phi^{T}\left(x_{1}, \widehat{x}_{2}\right) \phi\left(x_{1}, \widehat{x}_{2}\right) \leq 1$, we have

$$
\begin{aligned}
2 e^{T} P E_{2}(\Delta+\tilde{f}+b \hbar) \leq & \bar{L}\|e\|^{2}+\bar{D}+\|P\|^{2} \widetilde{\theta}^{T} \widetilde{\theta} \\
& +x_{1}^{2}(t-\tau(t)),
\end{aligned}
$$

where $\bar{L}=3+2\|P\| L_{f}+\|P\|^{2}, \tilde{\theta}=\theta^{*}-\theta, \bar{D}=\|P\|^{2} \Delta^{2}+$ $\|P\|^{2} \varepsilon^{* 2}$, and $\varepsilon$ is the fuzzy minimum approximation error, which satisfies $|\varepsilon| \leq \varepsilon^{*}$, and $\varepsilon^{*}$ is an unknown constant. Substituting (17) into (15) yields

$$
\dot{V}_{0} \leq-e^{T} Q e+\bar{L}\|e\|^{2}+\bar{D}+\|P\|^{2} \widetilde{\theta}^{T} \tilde{\theta} .
$$

\section{Adaptive Fuzzy Backstepping Control Design and Stability Analysis}

Define the following change of coordinates:

$$
\begin{gathered}
\chi_{1}=y, \\
\chi_{2}=\widehat{x}_{2}-\alpha_{1},
\end{gathered}
$$

where $\alpha_{1}$ is an intermediate control function which will be designed in the following.

Step 1. The time derivative of $\chi_{1}$ is

$$
\dot{\chi}_{1}=x_{2}=\widehat{x}_{2}+e_{2}=\chi_{2}+\alpha_{1}+e_{2} \text {. }
$$

Consider the following Lyapunov function candidate $V_{1}$ :

$$
V_{1}=V_{0}+\chi_{1}^{2}
$$

The time derivative of $V_{1}$ is

$$
\begin{aligned}
\dot{V}_{1} \leq & -e^{T} Q e+(\bar{L}+1)\|e\|^{2}+\bar{D}+\|P\|^{2} \widetilde{\theta}^{T} \widetilde{\theta}+x_{1}^{2}(t-\tau(t)) \\
& +2 \chi_{1}\left(\chi_{2}+\alpha_{1}+\frac{1}{2} \chi_{1}\right)
\end{aligned}
$$

Choose the intermediate control function $\alpha_{1}$ :

$$
\alpha_{1}=-\frac{1}{2} \chi_{1}-c_{1} \chi_{1}-\frac{e^{r \bar{\tau}}}{1-\tau^{*}} \chi_{1} .
$$

By substituting (23) into (22), we have

$$
\begin{aligned}
\dot{V}_{1} \leq & -e^{T} \mathrm{Q} e+(\bar{L}+1)\|e\|^{2}+\bar{D}+\|P\|^{2} \widetilde{\theta}^{T} \tilde{\theta} \\
& +x_{1}^{2}(t-\tau(t))+2 \chi_{1} \chi_{2}-2 c_{1} \chi_{1}^{2}-\frac{e^{r \bar{\tau}}}{1-\tau^{*}} \chi_{1}^{2} .
\end{aligned}
$$

Step 2. The time derivative of $\chi_{2}$ is

$$
\begin{aligned}
\dot{x}_{2}= & \dot{\hat{x}}_{2}-\dot{\alpha}_{1} \\
= & b u+\theta^{T} \varphi\left(x_{1}, \widehat{x}_{2}\right)+\widetilde{\theta}^{T} \varphi\left(x_{1}, \widehat{x}_{2}\right)-\widetilde{\theta}^{T} \varphi\left(x_{1}, \widehat{x}_{2}\right) \\
& +k_{2}\left(y-\widehat{x}_{1}\right)-\frac{\partial \alpha_{1}}{\partial x_{1}} e_{2}-\frac{\partial \alpha_{1}}{\partial x_{1}} \widehat{x}_{2} .
\end{aligned}
$$

Consider the following Lyapunov-Krasovskii functional

$$
V=V_{1}+\chi_{2}^{2}+\bar{V}+\frac{1}{2 \gamma} \widetilde{\theta}^{T} \tilde{\theta},
$$

where $\gamma$ is a positive design constant and $\bar{V}=\left(e^{r(\bar{\tau}-t)} /(1-\right.$ $\left.\left.\tau^{*}\right)\right) \int_{t-\tau(t)}^{t} e^{r s} x_{1}^{2}(s) d s$ with $r$ being a positive constant. 
The time derivative of $V$ is

$$
\begin{gathered}
\dot{V}=\dot{V}_{1}+2 \chi_{2}\left(b u+\theta^{T} \phi\left(x_{1}, \widehat{x}_{2}\right)+k_{2}\left(y-\widehat{x}_{1}\right)\right. \\
+\widetilde{\theta}^{T} \phi\left(x_{1}, \widehat{x}_{2}\right)-\widetilde{\theta}^{T} \phi\left(x_{1}, \widehat{x}_{2}\right) \\
\left.-\frac{\partial \alpha_{1}}{\partial x_{1}} e_{2}-\frac{\partial \alpha_{1}}{\partial x_{1}} \widehat{x}_{2}\right)+\frac{1}{\gamma} \widetilde{\theta}^{T} \dot{\tilde{\theta}}-r \bar{V} \\
+\frac{e^{r \bar{\tau}}}{1-\tau^{*}} x_{1}^{2}-x_{1}^{2}(t-\tau(t)) .
\end{gathered}
$$

By using Young's inequality, we have

$$
\begin{gathered}
-2 \chi_{2} \frac{\partial \alpha_{1}}{\partial x_{1}} e_{2} \leq\left(\chi_{2} \frac{\partial \alpha_{1}}{\partial x_{1}}\right)^{2}+\|e\|^{2}, \\
-2 \chi_{2} \widetilde{\theta}^{T} \phi\left(x_{1}, \widehat{x}_{2}\right) \leq \chi_{2}^{2}+\widetilde{\theta}^{T} \widetilde{\theta} .
\end{gathered}
$$

Substituting (28) into (27) yields

$$
\begin{gathered}
\dot{V} \leq-e^{T} Q e+(\bar{L}+2)\|e\|^{2}-r \bar{V}+\bar{D}+\left(\|P\|^{2}+1\right) \widetilde{\theta}^{T} \tilde{\theta} \\
-2 c_{1} \chi_{1}^{2}+2 \chi_{2}\left(\chi_{1}+\frac{1}{2} \chi_{2}+b u+\theta^{T} \phi\left(x_{1}, \widehat{x}_{2}\right)\right. \\
\left.+k_{2}\left(y-\widehat{x}_{1}\right)+\frac{1}{2} \chi_{2}\left(\frac{\partial \alpha_{1}}{\partial x_{1}}\right)^{2}-\frac{\partial \alpha_{1}}{\partial x_{1}} \widehat{x}_{2}\right) \\
+\widetilde{\theta}^{T}\left(2 \chi_{2} \phi\left(x_{1}, \widehat{x}_{2}\right)\right)-\frac{1}{\gamma} \dot{\theta} .
\end{gathered}
$$

Choose control input $u$ and the adaptive function $\theta$ as

$$
\begin{gathered}
u=\frac{1}{b}\left[-c_{2} \chi_{2}-\chi_{1}-\frac{1}{2} \chi_{2}-\theta^{T} \phi\left(x_{1}, \widehat{x}_{2}\right)-k_{2}\left(y-\widehat{x}_{1}\right)\right. \\
\left.-\frac{1}{2} \chi_{2}\left(\frac{\partial \alpha_{1}}{\partial x_{1}}\right)^{2}+\frac{\partial \alpha_{1}}{\partial x_{1}} \widehat{x}_{2}\right] \\
\dot{\theta}=\gamma\left[2 \chi_{2} \phi\left(x_{1}, \hat{x}_{2}\right)-\sigma \theta\right]
\end{gathered}
$$

where $c_{2}$ and $\sigma$ are positive design constants. Substituting (30) into (29) yields

$$
\begin{aligned}
\dot{V} \leq & -e^{T} Q e+(\bar{L}+2)\|e\|^{2}+\bar{D}-r \bar{V}-2 c_{1} \chi_{1}^{2}-2 c_{2} \chi_{2}^{2} \\
& +\sigma \widetilde{\theta}^{T} \theta+\left(\|P\|^{2}+1\right) \widetilde{\theta}^{T} \widetilde{\theta} .
\end{aligned}
$$

By using Young's inequality, the following inequality can be obtained:

$$
\sigma \widetilde{\theta}^{T} \theta=\sigma \widetilde{\theta}^{T}\left(\theta^{*}-\widetilde{\theta}\right) \leq-\frac{\sigma}{2} \widetilde{\theta}^{T} \widetilde{\theta}+\frac{\sigma}{2} \theta^{* T} \theta^{*} .
$$

Therefore, we have

$$
\begin{aligned}
\dot{V} \leq & -\left[\lambda_{\min }(Q)-\bar{L}-2\right]\|e\|^{2}+\bar{D}-2 c_{1} \chi_{1}^{2}-2 c_{2} \chi_{2}^{2} \\
& -\left(\frac{\sigma}{2}-\left(\|P\|^{2}+1\right)\right) \widetilde{\theta}^{T} \widetilde{\theta}+\frac{\sigma}{2} \theta^{* T} \theta^{*}
\end{aligned}
$$

where $\lambda_{\min }(Q)$ is the smallest eigenvalue of $Q$. Choose $\rho=$ $\lambda_{\text {min }}(Q)-\bar{L}-2>0$ and $q=(\sigma / 2)-\left(\|P\|^{2}+1\right)>0$. Let $\beta=\min \left\{\rho / \lambda_{\max }(P), c_{1} / 2, c_{2} / 2, \gamma q, r\right\}, \bar{\pi}=\bar{D}+(\sigma / 2) \theta^{* T} \theta^{*}$, and (33) can be expressed as

$$
\dot{V} \leq-\beta V+\bar{\pi} .
$$

Equation (34) can be rewritten as

$$
V(t) \leq V(0) e^{-\beta t}+\frac{\bar{\pi}}{\beta} .
$$

According to (35), it can be shown for the signals that $x, e, \chi_{2}, \theta_{2}, \widehat{w}$, and $u$ are SGUUB. $|y(t)| \leq \sqrt{V(0)} e^{-\beta t}+\sqrt{\pi / \beta}$ and $\|e(t)\| \leq\left(\sqrt{V(0)} e^{-\beta t}+\sqrt{\pi / \beta}\right) / \sqrt{\lambda_{\max }(P)}$. It is worth noting that $t \rightarrow \infty, e^{-\beta t} \rightarrow 0, \lim _{t \rightarrow \infty}\left|y(t)-y_{r}(t)\right|=$ $\sqrt{\pi / \beta}$, and $\lim _{t \rightarrow \infty}\|e(t)\|=\sqrt{\pi / \beta} / \sqrt{\lambda_{\max }(P)}$

\section{Simulation Study}

The parameters of a certain war ship are as follows: the length between perpendiculars is $98 \mathrm{~m}$, the width of ship is $10.2 \mathrm{~m}$, draught is $3.1 \mathrm{~m}$, tonnage is $1458 \mathrm{t}$, the area of fin is $5.22 \mathrm{~m}^{2}$, the acting force arm of fin stabilizer is $3.46 \mathrm{~m}$, the lift coefficient of fin stabilizer is 3.39 , flooding angle is $43^{\circ}$, initial metacentric height is $1.15 \mathrm{~m}$, designed speed is $18 \mathrm{kt}$, test coefficients are $n_{1}=0.031$ and $n_{2}=0.051$, and $\tau=0.5(1+\sin (t))$.

In the simulation studies, the if-then rules are chosen as

$$
\begin{aligned}
& R^{1}: \quad \text { If } x_{1} \text { is } F_{1}^{1} \text { and } \widehat{x}_{2} \text { is } F_{2}^{1} \text {, then } y \text { is } G^{1} ; \\
& R^{2}: \quad \text { If } x_{1} \text { is } F_{1}^{2} \text { and } \widehat{x}_{2} \text { is } F_{2}^{2} \text {, then } y \text { is } G^{2} ; \\
& R^{3}: \quad \text { If } x_{1} \text { is } F_{1}^{3} \text { and } \widehat{x}_{2} \text { is } F_{2}^{3} \text {, then } y \text { is } G^{3} ; \\
& R^{4}: \quad \text { If } x_{1} \text { is } F_{1}^{4} \text { and } \widehat{x}_{2} \text { is } F_{2}^{4} \text {, then } y \text { is } G^{4} ; \\
& R^{5}: \quad \text { If } x_{1} \text { is } F_{1}^{5} \text { and } \widehat{x}_{2} \text { is } F_{2}^{5} \text {, then } y \text { is } G^{5},
\end{aligned}
$$

where fuzzy sets are chosen as $F_{1}^{1}=(\mathrm{NL}), F_{2}^{1}=(\mathrm{NL}), F_{1}^{2}=$ (NS), $F_{2}^{2}=(\mathrm{NS}), F_{1}^{3}=(\mathrm{ZE}), F_{2}^{3}=(\mathrm{ZE}), F_{1}^{4}=(\mathrm{PS}), F_{2}^{4}=$ (PS), $F_{1}^{5}=(\mathrm{PL}), F_{2}^{5}=(\mathrm{PL})$, which are defined over the interval $[-2,2]$ for variables $x_{1}$ and $\widehat{x}_{2}$, respectively. NL, NS, $\mathrm{ZO}, \mathrm{PS}$, and PL denote negative large, negative small, zero, positive small, and positive large, respectively.

In this section, the fuzzy membership functions are determined by using the expertise and experimental result. Center points of these membership functions are selected as $-2,-1$, 0,1 , and 2 , respectively. The corresponding fuzzy membership functions are given by

$$
\begin{aligned}
& \mu_{F_{1}^{l}}\left(x_{1}\right)=\exp \left[-\frac{\left(x_{1}-3+l\right)^{2}}{4}\right], \\
& \mu_{F_{2}^{l}}\left(\hat{x}_{2}\right)=\exp \left[-\frac{\left(\hat{x}_{2}-3+l\right)^{2}}{4}\right],
\end{aligned}
$$

Define fuzzy basis functions as

$$
\phi\left(x_{1}, \widehat{x}_{2}\right)=\frac{\mu_{F_{1}^{l}} \mu_{F_{2}^{l}}}{\sum_{k=1}^{5}\left[\mu_{F_{1}^{k}} \mu_{F_{2}^{k}}\right]}, \quad l=1, \ldots, 5 .
$$




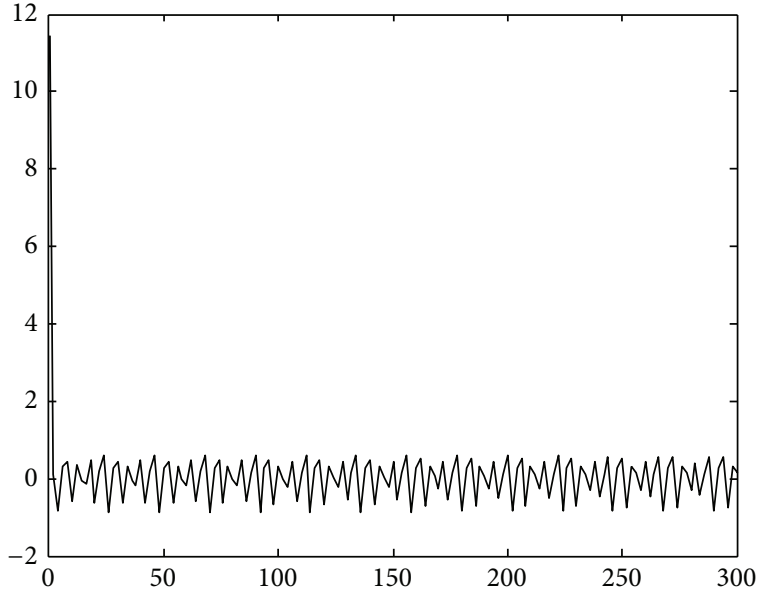

(s)

FIgURE 1: Ship roll angle $\varphi$.

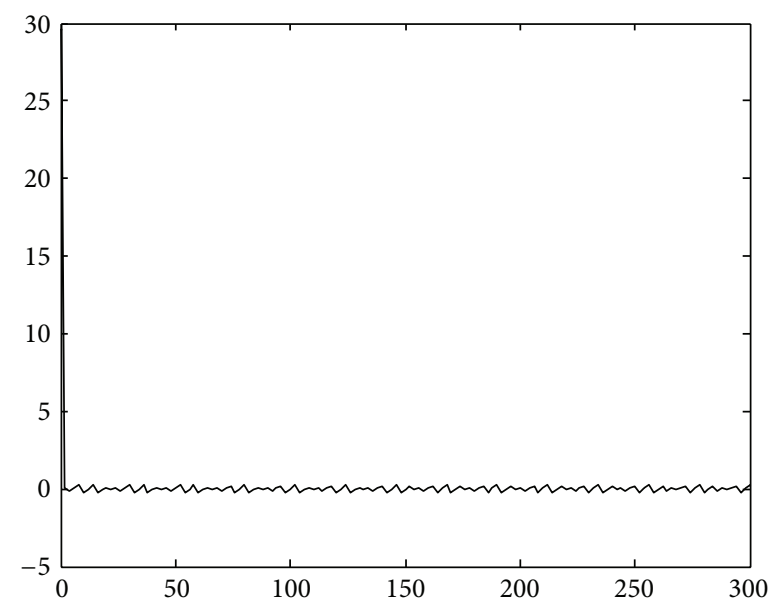

(s)

Figure 2: Fin control angle $a_{f}$.

The design parameters are chosen as $Q=\operatorname{diag}\{30,30\}, k_{1}=$ $2, k_{2}=2, \sigma=32, \gamma=20, r=1, \tau^{*}=0.6, \bar{\tau}=1.1, c_{1}=c_{2}=$ 4. The initial conditions are given as $\varphi(0)=11.26^{\circ}, \dot{\varphi}(0)=$ $5.63^{\circ}$, and the other initial values are chosen as zeros. The simulation results are shown in Figures 1 and 2.

\section{Conclusions}

In this paper, the time-delay ship roll stabilization by fin control system has been considered. Assuming that angular velocity in roll cannot be measured, an adaptive fuzzy outputfeedback control has been investigated. The fuzzy logic system was used to approximate the uncertain term of the controlled system, and a fuzzy state observer was designed to estimate the unmeasured states. By utilizing the fuzzy state observer, an adaptive fuzzy output-feedback control approach was developed for fin control system. It is proven that the proposed control approach can guarantee that all the signals in the closed-loop system are SGUUB.
In the future research, the input constraints of the fin control system should be considered. In fact, the input variable of the fin control system is limited in a certain range. The adaptive fuzzy output-feedback controller with the input saturation will be researched in the future.

\section{Conflict of Interests}

The author of the paper has declared no conflict of interests.

\section{Acknowledgments}

This work was supported in part by the State Key Laboratory of Synthetical Automation for Process Industries (PALN201206) and the Natural Science Fundamental of Liaoning Province.

\section{References}

[1] A. R. J. M. Lloyd, Seakeeping: Ship Behavior in Rough Weather, Ellis Horwood, Chichester, UK, 1989.

[2] G. N. Roberts and D. R. Towill, "Multivariable control of warship maneuvering," in Proceedings of the 10th IFAC World Congress, pp. 220-225, Munich, Germany, 1987.

[3] R. Sutton, G. N. Robert, and S. R. Dearden, "Design study of a fuzzy controller for ship roll stabilization," Electronics and Communication Engineer Journal, vol. 1, no. 4, pp. 159-166, 1989.

[4] L. Fortuna and G. Muscato, "A roll stabilization system for a monohull ship: modeling, identification and adaptive control," IEEE Transactions on Control System Technology, vol. 4, no. 1, pp. 18-28, 1996.

[5] N. A. Hickney, M. J. Grimble, M. Johnson, R. Katebi, and D. Wood, "H-infinity fin roll stabilization control system design," in Proceedings of the 3rd IFAC Workshop on Control Applications in Marine System, pp. 304-311, Trondheim, Norway, 1995.

[6] C.-Y. Tzeng and C.-Y. Wu, "On the design and analysis of ship stabilizing fin controller," Journal of Marine Science and Technology, vol. 8, no. 2, pp. 117-124, 2000.

[7] S. C. Tong, Y. Li, Y. M. Li, and Y. J. Liu, "Observer-based adaptive fuzzy backstepping control for a class of stochastic nonlinear strict-feedback systems," IEEE Transactions on Systems, Man and Cybernetics B, vol. 41, no. 6, pp. 1693-1704, 2011.

[8] H. Wang, B. Chen, and C. Lin, "Adaptive neural tracking control for a class of perturbed pure-feedback nonlinear systems," Nonlinear Dynamics, vol. 72, no. 1-2, pp. 207-220, 2013.

[9] S. C. Tong, C. Y. Li, and Y. M. Li, "Fuzzy adaptive observer backstepping control for MIMO nonlinear systems," Fuzzy Sets and Systems, vol. 160, no. 19, pp. 2755-2775, 2009.

[10] J. Yu, H. Yu, B. Chen, J. Gao, and Y. Qin, "Direct adaptive neural control of chaos in the permanent magnet synchronous motor," Nonlinear Dynamics, vol. 70, no. 3, pp. 1879-1887, 2012.

[11] S. C. Tong, T. Wang, Y. M. Li, and B. Chen, "A combined backstepping and stochastic small-gain approach to robust adaptive fuzzy output feedback control," IEEE Transactions on Fuzzy Systems, vol. 21, no. 2, pp. 314-327, 2013.

[12] X.-P. Wang and X.-K. Zhang, "Fin stabilizer control based on backstepping and closed-loop gain shaping algorithms," Journal of Dalian Maritime University, vol. 34, no. 3, pp. 89-92, 2008.

[13] Y. T. Zhang, W. R. Shi, and M. B. Qiu, "Sliding backstepping control for fin stabilizer with nonlinear disturbance observer," Control and Decision, vol. 25, no. 8, pp. 1254-1259, 2010. 
[14] S. Tong and Y. Li, "Observer-based fuzzy adaptive control for strict-feedback nonlinear systems," Fuzzy Sets and Systems, vol. 160, no. 12, pp. 1749-1764, 2009.

[15] Y. M. Li, S. C. Tong, Y. J. Liu, and T. S. Li, "Adaptive fuzzy robust output feedback control of nonlinear systems with unknown dead zones based on small-gain approach," IEEE Transactions on Fuzzy Systems, vol. 22, no. 1, pp. 164-176, 2014.

[16] S. C. Tong and Y. M. Li, "Adaptive fuzzy output feedback tracking backstepping control of strict-feedback nonlinear systems with unknown dead zones," IEEE Transactions on Fuzzy Systems, vol. 20, no. 1, pp. 168-180, 2012.

[17] H. Q. Wang, B. Chen, X. P. Liu, K. F. Liu, and C. Lin, "Robust adaptive fuzzy tracking control for pure-feedback stochastic nonlinear systems with input constraints," IEEE Transaction on Cybernetics, vol. 43, no. 6, pp. 2093-2104, 2013.

[18] Q. Zhou, P. Shi, S. Y. Xu, and H. Y. Li, "Adaptive output feedback control for nonlinear time-delay systems by fuzzy approximation approach," IEEE Transactions on Fuzzy Systems, vol. 21, no. 2, pp. 301-313, 2013.

[19] H. Y. Li, J. Y. Yu, H. H. Liu, and C. Hilton, "Adaptive sliding mode control for nonlinear active suspension vehicle systems using T-S fuzzy approach," IEEE Transactions on Industrial Electronics, vol. 60, no. 8, pp. 3328-3338, 2013.

[20] L. X. Wang, Adaptive Fuzzy Systems and Control, Prentice Hall, Englewood Cliffs, NJ, USA, 1994. 


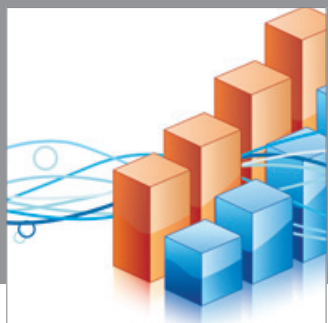

Advances in

Operations Research

mansans

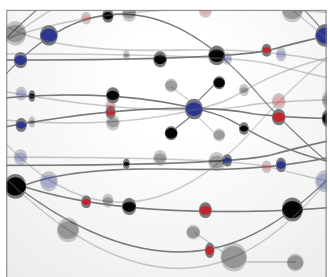

The Scientific World Journal
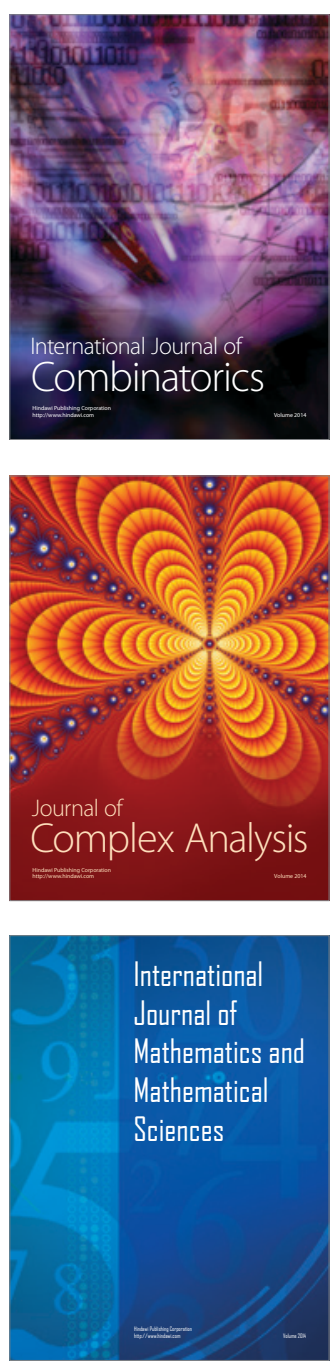
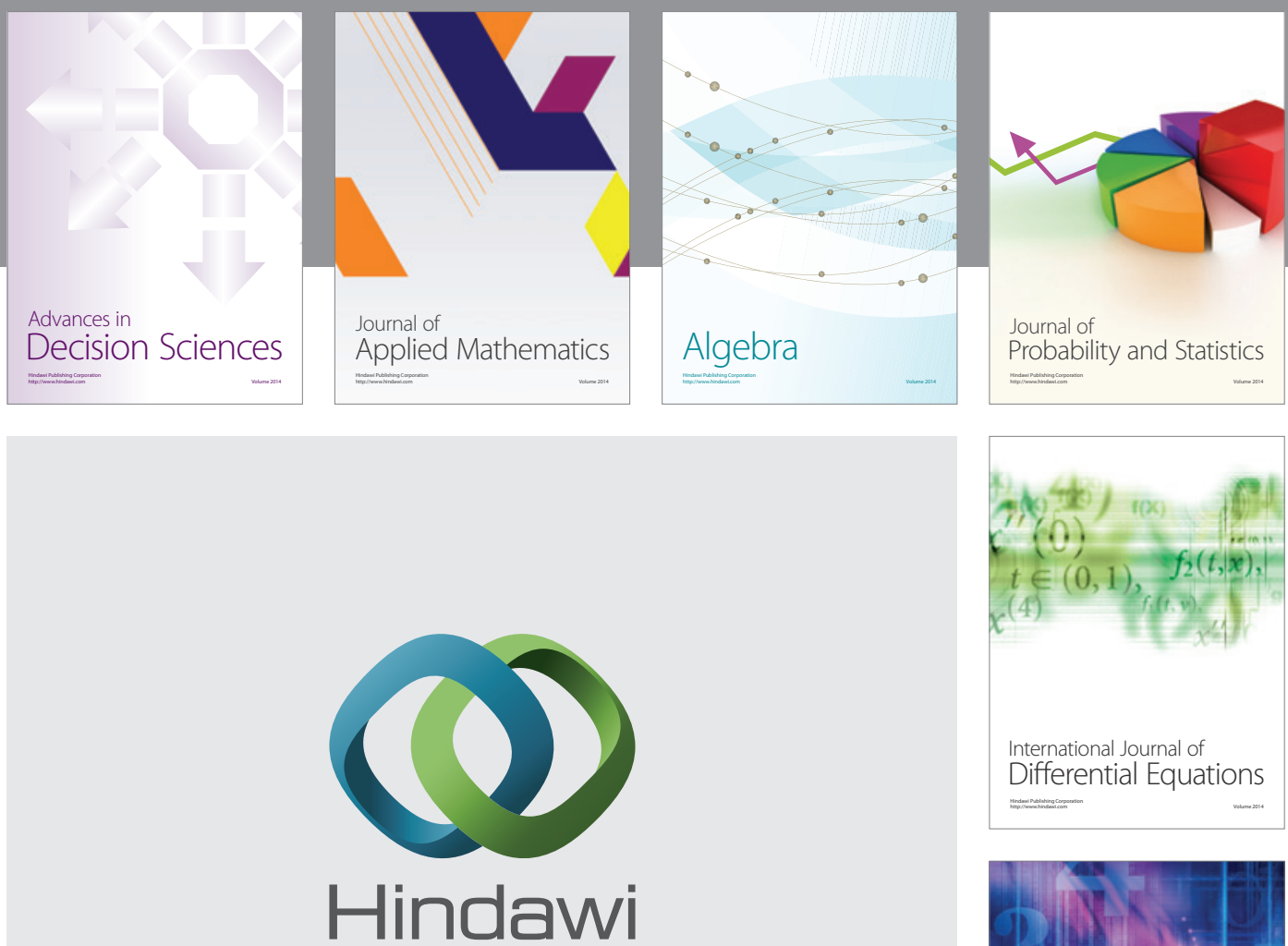

Submit your manuscripts at http://www.hindawi.com
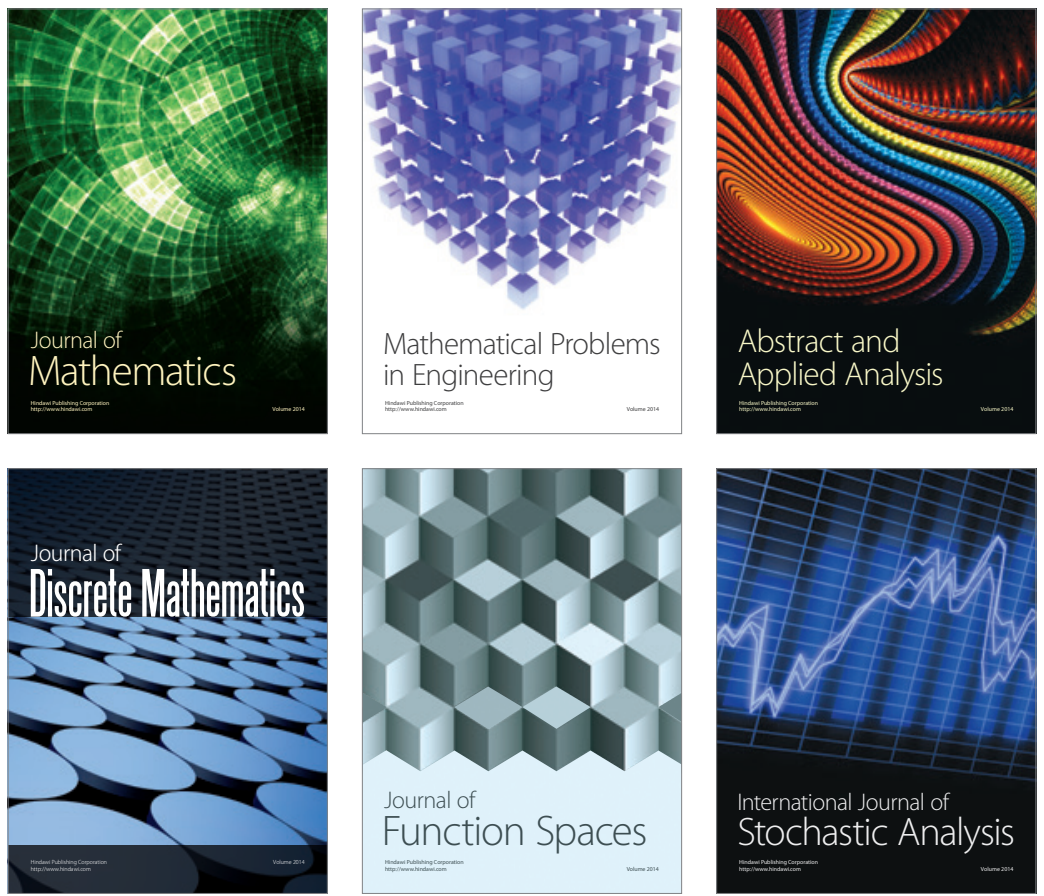

Journal of

Function Spaces

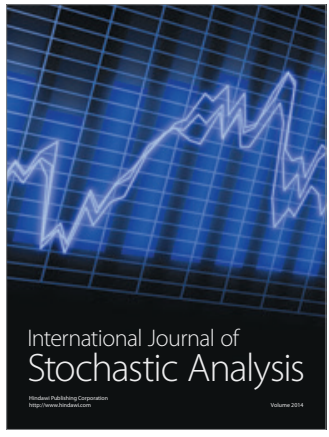

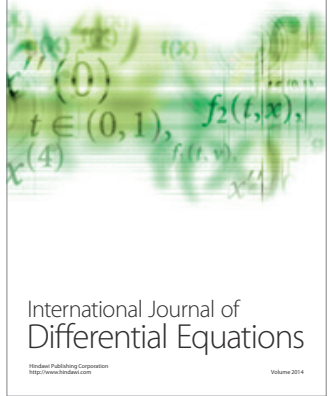
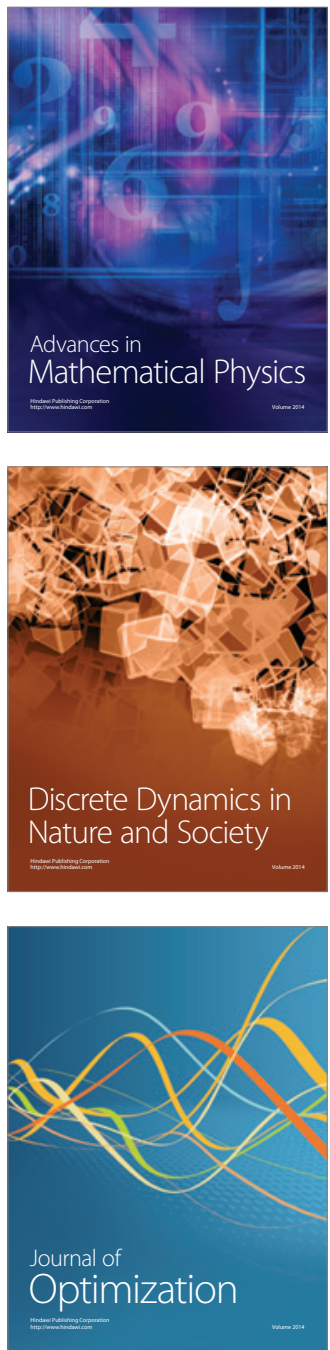